\title{
Periprosthetic fractures and complicated arthroplasties
}

\author{
Moussa Hamadouche $^{1}$ - Luis Lopez-Duran Stern ${ }^{2}$
}

Published online: 18 August 2015

(C) SICOT aisbl 2015

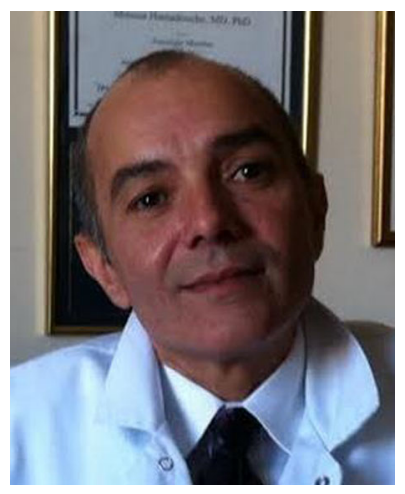

Moussa Hamadouche

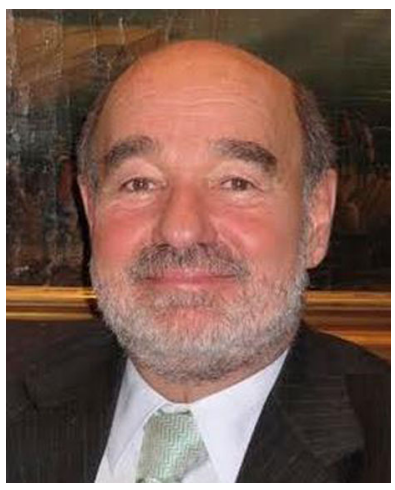

Luis Lopez-Duran Stern
Periprosthetic fractures (PPF) have become a frequent complication of total hip and knee replacements with rates up to $15 \%$ in major registries. Other artificial articulations such as the shoulder and the elbow, although less frequently concerned, are not immune to this complication. This observation is related to the increased number of procedures performed annually, with projection showing that the growth will continue exponentially in the next decades due to aging population. The number of revision procedures increases also with the associated bone loss, that is a major risk factor for PPF, and that will probably continue to rise. It is probable that this complication will become in the near future a major public health issue with high rising costs associated to the treatment.

Moussa Hamadouche moussah@club-internet.fr

1 Hospital Cochin, University of Paris 5, Paris, France

2 Hospital San Carlos, University of Madrid, Madrid, Spain
It becomes therefore evident that surgeons should be aware of PPF and complicated revisions to advise the patients accordingly, making this special issue of International Orthopaedics necessary. We have put together a sum of papers concerning the subject from around the world and from major experts. There are papers on the biomechanics and stability of the revision stems $[1,2]$, as it is important for surgeons to understand how this complication can occur, and hence how to avoid conditions that would lead to PFF, especially stress risers. Periprosthetic fractures around the hip and the knee are extensively described with up to date detailed treatment options, from various fixation modes of well fixed implants to revision. A specific situation is studied by Zettl et al. [3] concerning the acetabular fractures in the elderly with a description of a minimally invasive technique in this patient population with co-morbid conditions. A very interesting paper coming from China (Huang and coll) proposes variations and adds to the existing classifications [4]. Tatu Makkinen from Finland and Canada brings an original biomechanical study comparing four methods of fixation after periprosthetic 
supracondylar fractures of the femur after knee arthroplasty [5]. Claudia Sidler-Maier and James Wadell from Canada bring a thorough literature review and discuss the current state of the art in this field of treating complications and traumatic events on fragile prosthetic joints [6]. Märdian and colleagues discuss the outcomes after PPF around the hip [7]. Baba Tomonori from Japan discusses his own classification and its inter-observer variability [8] while Yassem and Haddad [9] as well as the next three papers coming from SouthKorea [10], Sweden [11] and France [12] discuss different aspects related to PPF in femur. The paper from Barut et al. [13] provide insights of PPF around tumor prosthesis, as this situation adds to the complexity of the fractures associated to mega- or composite implants, a previous resection procedure, making internal fixation attractive but with high risk of revision. As a reader you may find useful the paper authored by Schmolders and coll. [14] concerning the value of the Charlson comorbidity index in the assessment of revision surgeries. The Romanian team from Tg. Mures is bringing a paper about complicated acetabular reconstructions in protrusions [15]. There are also some invited papers that arrived late or too late for being included in this issue. They will be available online and in the printed issues of October and November.

We were very honored to guest edit this issue, and hope it will become a landmark and useful issue to the orthopaedic community.

\section{References}

1. Kinkel S, Nadorf J, Thomsen MN, Heisel C, Jahnke A, Kretzer JP, Jakubowitz E (2015) Fixation pattern of conical and cylindrical modular revision hip stems in different size bone defects. Int Orthop. doi:10.1007/s00264-015-2869-5

2. Gwinner C, Märdian S, Dröge T, Schulze M, Raschke MJ, Stange R (2015) Bicortical screw fixation provides superior biomechanical stability but devastating failure modes in periprosthetic femur fracture care using locking plates. Int Orthop. doi:10.1007/s00264-0152787-6

3. Zettl R, Eschbach D, Ruchholtz S (2015) Management of periprosthetic acetabular fractures in elderly patients-a minimally invasive approach. Int Orthop. doi:10.1007/s00264-015-2936-y
4. Huang JF, Shen JJ, Chen JJ, Zheng Y, Du WX, Liu FC, Tong PJ (2015) New fracture pattern focusing on implant fracture for periprosthetic femoral fractures. Int Orthop. doi:10.1007/s00264015-2830-7

5. Mäkinen TJ, Dhotar HS, Fichman SG, Gunton MJ, Woodside M, Safir O, Backstein D, Willett TL, Kuzyk PR (2015) Periprosthetic supracondylar femoral fractures following knee arthroplasty: a biomechanical comparison of four methods of fixation. Int Orthop. doi: 10.1007/s00264-015-2764-0

6. Sidler-Maier CC, Waddell JP (2015) Incidence and predisposing factors of periprosthetic proximal femoral fractures: a literature review. Int Orthop. doi:10.1007/s00264-015-2721-y

7. Märdian S, Schaser KD, Gruner J, Scheel F, Perka C, Schwabe P (2015) Adequate surgical treatment of periprosthetic femoral fractures following hip arthroplasty does not correlate with functional outcome and quality of life. Int Orthop. doi:10.1007/s00264-0152673-2

8. Baba T, Homma Y, Ochi H, Kobayashi H, Matsumoto M, Sakamoto Y, Kuwahara H, Maeda K, Kaneko K (2015) Higher reliability and validity of Baba classification with computerised tomography imaging and implant information for periprosthetic femoral fractures. Int Orthop. doi:10. 1007/s00264-015-2674-1

9. Yasen AT, Haddad FS (2014) The management of type B1 periprosthetic femoral fractures: when to fix and when to revise. Int Orthop. doi:10.1007/s00264-014-2617-2

10. Lim SJ, Lee KJ, Min BW, Song JH, So SY, Park YS (2014) High incidence of stem loosening in association with periprosthetic femur fractures in previously well-fixed cementless grit-blasted tapered-wedge stems. Int Orthop. doi:10.1007/s00264-014-2586-5

11. Inngul C, Enocson A (2014) Postoperative periprosthetic fractures in patients with an Exeter stem due to a femoral neck fracture: cumulative incidence and surgical outcome. Int Orthop. doi:10. 1007/s00264-014-2570-0

12. Ehlinger M, Bahlau D, Rahme M, Adam P, Bonnomet F (2015) Has a patient type with peri-prosthetic femoral fractures evolved? Int Orthop. doi:10.1007/s00264-015-2873-9

13. Barut N, Anract P, Babinet A, Biau D (2015) Peri-prosthetic fractures around tumor endoprostheses: a retrospective analysis of eighteen cases. Int Orthop. doi:10.1007/s00264-015-2915-3

14. Schmolders J, Friedrich MJ, Michel R, Strauss AC, Wimmer MD, Randau TM, Pennekamp PH, Wirtz DC, Gravius S (2015) Validation of the Charlson comorbidity index in patients undergoing revision total hip arthroplasty. Int Orthop. doi:10.1007/s00264015-2810-y

15. Zuh SG, Zazgyva A, Gergely I, Pop TS (2015) Acetabuloplasty with bone grafting in uncemented hip replacement for protrusion. Int Orthop. doi:10.1007/s00264-015-2804-9 